\title{
ACUTE EPIGLOTTITIS: CURRENT MANAGEMENT AND REVIEW
}

\section{R. HaNnallah and J.K. Rosales}

ACUTE EPIGLOTTITIS has always been a current issue in paediatric practice involving anaesthetists, otolaryngologists, and paediatricians. Judging by the number of reports appearing in recent literature, there is continuing intense interest in this condition and this has resulted in a better understanding of the patho-physiology of the disease and in approaching the management of these very sick children by prolonged nasotracheal intubation.

The disease was first described in 1941 by Sinclair in the Journal of the American Medical Association. ${ }^{1}$ It is a clinical pathological entity which should more correctly be called supraglottitis because the arytenoids and ary-epiglottic folds are usually affected and become swollen and stiff with inflammatory oedema. ${ }^{2}$ Epiglottitis is primarily a disease of childhood. In our series it was most commonly seen between the ages of three and five years (Figure 1). The oldest patient was ten years of age and the youngest eleven months. However, it has been reported to occur in adults on rare occasions. ${ }^{3}$ Seasonal incidence reported also varies. This may be explained partially by local differences in weather conditions. Our cases were seen mainly during summer and autumn (Figure 2). There is a tremendous variation in the yearly incidence and sometimes the disease seems to come almost in epidemic form. There was little sex difference noticed among our patients, boys being affected slightly more often than girls (Figure 3 ).

\section{Clinical Presentation}

The onset of the disease is usually abrupt with a very brief history of high fever, severe sore throat, and difficulty in swallowing. The history is seldom more than 10 to 12 hours. This is in contrast to laryngo-tracheo-bronchitis or croup,

R. Hannallah, M.D., F.R.C.P.(C), Department of Anaesthesia, Montreal Children's Hospital; Assistant Professor, McGill University.

J.K. Rosales, M.D., F.R.C.P.(C), Director, Department of Anaesthesia, Montreal Children's Hospital; Associate Professor, McGill University, Montreal, P.Q., Canada.

Reprint requests to Dr. R. Hannallah. when there is usually a longer history of cold-like symptoms preceding the manifestations of upper airway obstruction. Typically the mother will say that the child went to bed apparently well and woke up at night with difficulty in breathing, high fever and sore throat. ${ }^{2}$ If there is stridor, it is usually inspiratory and, since the subglottic structures are usually unaffected, there is little or no hoarseness. The clinical appearance of the child is classical (Figure 4), and is easily diagnosed. The child appears ill and insists on sitting up and leaning forward in an attempt to improve air flow past the swollen epiglottis. The mouth is open, with the tongue protruding. Frequently the child will be drooling because of difficulty and pain on swallowing. Besides the high fever, other signs of generalized toxaemia may include tachycardia, a flushed face, and dehydration if the history is prolonged.

In some cases of early epiglottitis the clinical picture may not be so conclusive. There are two ways of confirming the diagnosis:

\section{Lateral X-ray of the Neck $^{4}$}

The X-Ray will usually show the swollen epiglottis and aryepiglottic folds (Figure 5). The valleculae may be obliterated but subglottic structures are usually clear. However, there have been many objections to the idea of taking $X$-rays in these patients, as it may delay treatment. We feel that a lateral view of the neck, although not necessary in all cases, could be helpful in some
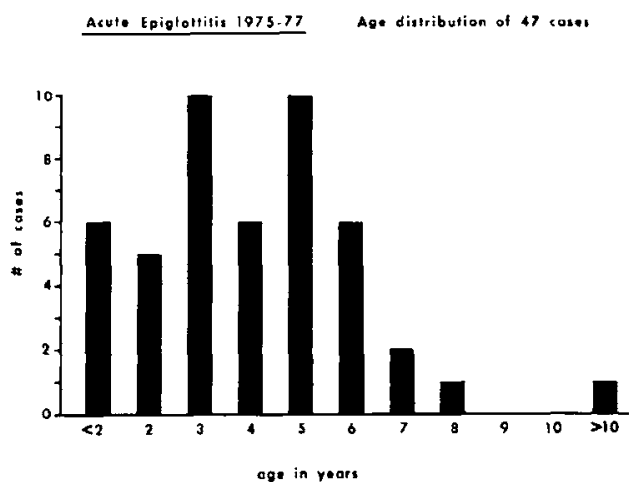

FIGURE 1 Age incidence of acute epiglottitis.

Canad. Anaesth. Soc. J., vol. 25, no. 2, March 1978 


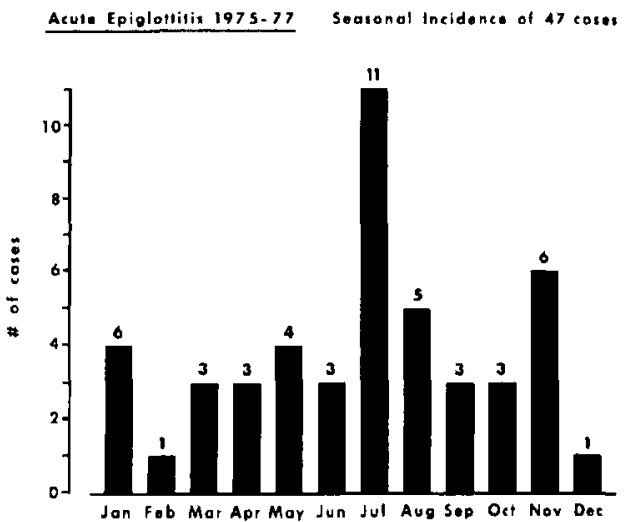

FIgURE 2 Seasonal incidence of acute epiglottitis.

cases. It may also help to diagnose an unsuspected foreign body in the larynx. In our protocol, an X-ray may be taken only in the intensive care area with the patient sitting up and with a physician in attendance. Under no circumstances should a child with suspected epiglottitis be sent to the radiology department or laid on the back!

\section{Direct Laryngoscopy}

The only way to verify the diagnosis of acute epiglottitis is to examine the larynx and actually to see the inflamed supraglottic structures. This should be done in all cases, but only in an operating room with adequate staff and equipment to

Acute Epiglottitis 1975.77

Sex Incidence in 47 cases

26

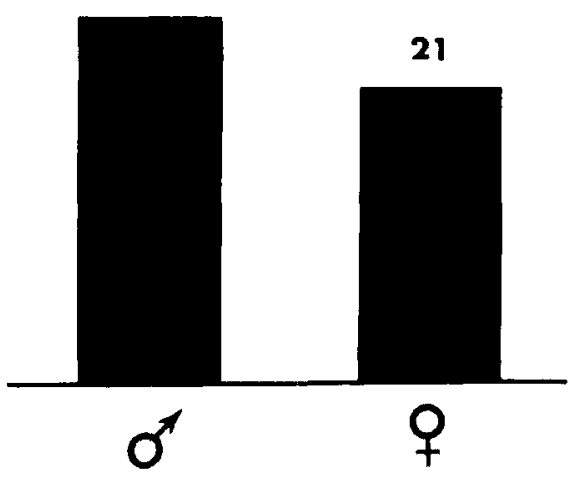

FIGURE 3 Sex incidence of acute epiglottitis.

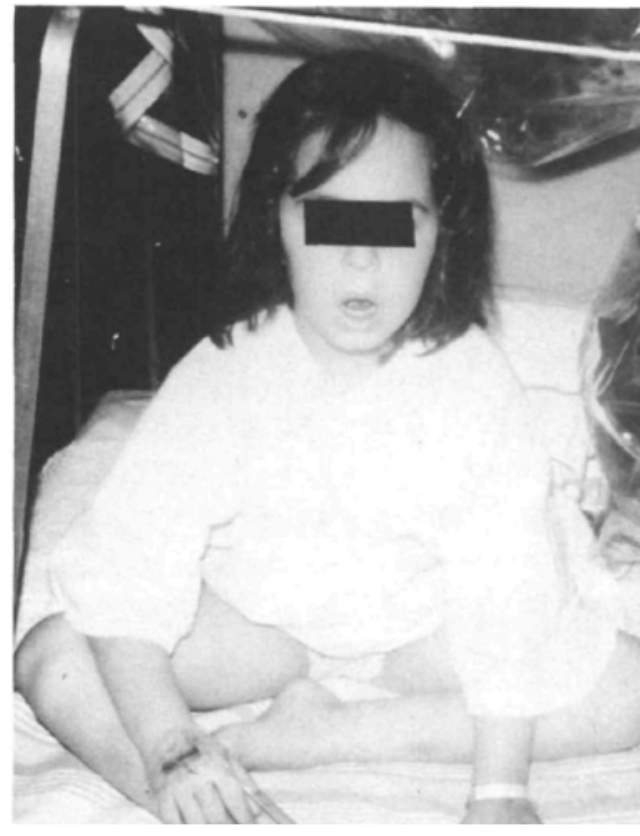

FIGURE 4 Patient with epiglottitis showing typical posture.

handle an upper airway obstruction. Under no other circumstances should laryngoscopy be attempted as it can induce complete airway obstruction and fatal asphyxiation.

The reason for sudden fatal upper airway obstruction in these children is not completely understood. Different mechanisms have been proposed:

(a) Mechanical laryngeal obstruction resulting from the enlarged epiglottis being sucked into the laryn $\mathrm{x}$ will produce complete airway obstruction. This may occur if the child is forced to lie on the back. However, the swollen supraglottic structures usually become quite stiff from the accumulated oedema fluid which would, in fact, limit the movement of the epiglottis. The concept of a large flabby epiglottis waiting to fall into the larynx and to obstruct it at any moment has been recently questioned. ${ }^{4}$

(b) Laryngeal spasm may result from irritation of the inflamed larynx by saliva which accumulates in the vallecula and which might spill onto the vocal cords if the child assumes the supine position.

(c) Respiratory arrest may result from extreme fatigue and exhaustion in a toxic child who has been working extremely hard to maintain airexchange. ${ }^{6}$ 


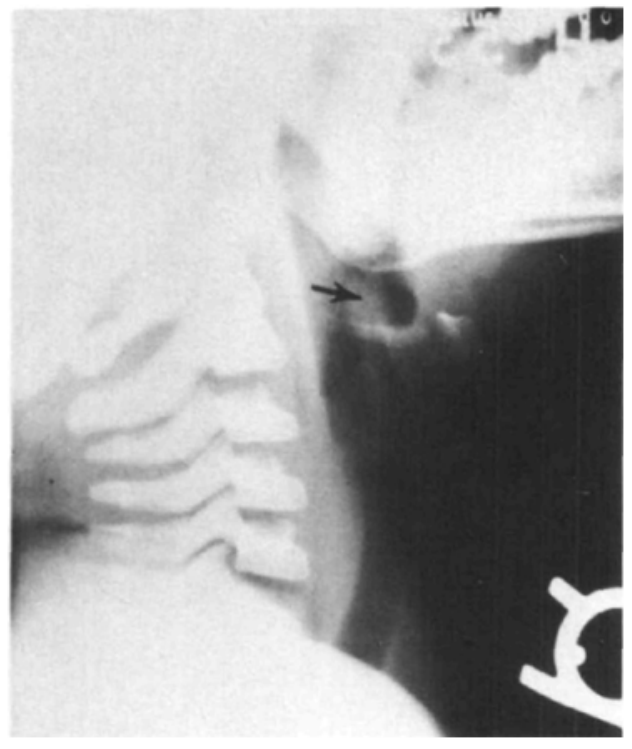

Figure 5(a) X-ray appearance of larynx. Normal.

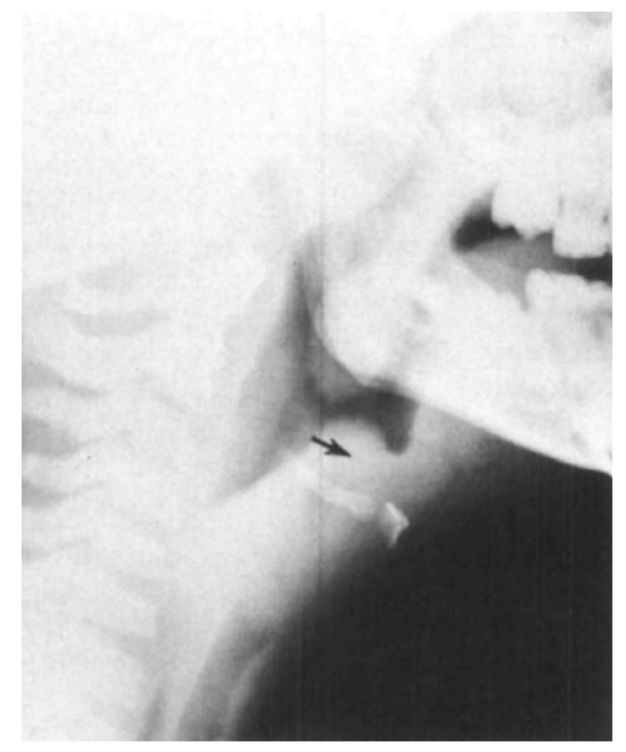

FIGURE 5(b) X-ray appearance of larynx. Epiglottitis.

Whatever the reason, it is a fact that children with acute epiglottitis can go into respiratory arrest suddenly and without much warning. For that reason, once the diagnosis has been made these patients should have an artificial airway inserted without delay.

\section{BACTERIOLOGY}

The causative organism in acute epiglottitis is believed to be haemophilus influenzae type $B$. Although the main focus of infection is in the supraglottic structures, the disease is really a generalized toxaemia. When blood cultures were examined in these patients, 91 per cent were positive for haemophilus influenzae type $B$. Throat cultures are less reliable and show no growth or normal flora in most cases.

\section{Principles of Management}

Management of acute epiglottitis demands the establishment of a secure airway and treatment of infection and the accompanying toxaemia.

Before July 1975, all patients admitted to the Montreal Children's Hospital with acute epiglottitis underwent a tracheostomy to secure the airway. For comparative purposes, 61 patients treated in this manner between the years 1966 and 1974 were reviewed $^{7}$ and were later compared with a prospective evaluation of a series of patients in whom nasotracheal intubation was used as an alternative for airway support.

During the two-year period from July 1975 to July 1977, 47 patients were treated for acute epiglottitis at the Montreal Children's Hospital. They all had naso-tracheal intubation instituted under general anaesthesia. Intubation was maintained for periods ranging from 17 hours to three days with a mean duration of 48 hours. Different members of the department of anaesthesia were involved and a pre-set protocol was followed. The protocol was designed with the following facts in mind:

Acute epiglottitis is a self-limiting but potentially fatal disease.

If the condition is suspected in the emergency room, the child should be taken immediately to the intensive care area by a physician experienced in airway management.

When the diagnosis of acute epiglottitis is made, an artificial airway must be established in all cases.

Management of these patients is a team effort involving paediatricians, otolaryngologists and anaesthetists.

Medical treatment is started after the artificial airway has been secured.

\section{Details of management}

When a patient is seen in the emergency room with suspected acute epiglottitis, the child is 
taken immediately by the admitting physician and nurse to the intensive care unit. The senior anaesthetist in the hospital is called to see the child and the otolaryngology service is notified. In the intensive care area the case is reviewed. The child is kept sitting up, usually on the mother's lap, and oxygen is given by mask as required. No attempts at either laryngoscopy or the starting of an intravenous infusion are made at this time. Lateral and antero-posterior radiographs of the neck area are usually taken in the intensive care unit with the child still sitting up. This may help to establish the diagnosis in some border-line or early cases and will rule our severe croup or laryngeal foreign bodies as possible causes of the respiratory distress. At the same time, the history is being taken. The child is never sent to the X-ray department for the examination because sudden complete airway obstruction may occur at any time.

Once the diagnosis is made, or if the condition cannot be ruled out, the child is taken to the operating room for direct laryngoscopy under general anaesthesia carried out by the anaesthetist and a naso-tracheal tube is left in place.

The detailed management in the operating room is as follows. After the theatre is prepared to handle a patient with upper airway obstruction, including preparation for rigid bronchoscopy and possible tracheostomy, the child is brought in and a precordial stethoscope and a cardioscope are attached. Inhalation induction with oxygen and halothane by mask is started with the child still sitting up. THERE is NO PLACE FOR INTRAYENOUS INDUCTION AGENTS OR THE USE OF MUSCLE RELAXANTS IN THESE PATIENTS. Once the child is drowsy, the position is changed to supine. In most cases signs of airway obstruction increase in that position, but we find that gentle assisting of inspiration by positive pressure usually improves air exchange. An intravenous cannula is then inserted in a lower extremity, usually in the long saphenous vein.

When the surgical stage of anaesthesia is achieved, direct laryngoscopy is done, thus establishing the diagnosis (Figure 6). A throat swab is taken from the epiglottitis for bacterial culture and $1 \mathrm{ml}$ of four per cent lidocaine is sprayed onto the larynx. A tracheal tube of appropriate size is then introduced (Table I). In most cases we prefer to begin with an orotracheal tube because it is quicker to insert, to get the child settled and the airway suctioned and then to change to a nasotracheal tube. It is very important to understand that a very small diameter tube is all that is needed to "splint" the inflamed epiglottis and to

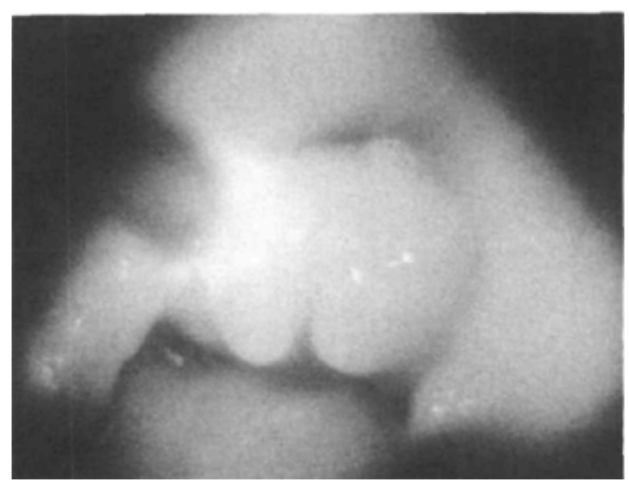

FIGURE 6 Laryngoscopic view of acute epiglottitis.

establish a comfortable airway. A larger tube is not only unnecessary, but also predisposes to the possible development of serious laryngeal complications. ${ }^{8}$ For some reason this concept is difficult to teach, but we insist on adhering to the table of suggested tube sizes in all cases. Both Portex* and Shiley† nasotracheal tubes have been used with good results. Once the tube is in place, it is important to guarantee that it will stay there for the desired period. We have found the following to be effective in preventing accidental extubation:

1. After auscultation to confirm the correct position of the tube, the skin of the upper lip and cheeks is painted with tincture of benzoin. Waterproof adhesive tape cut into half-inch strips is used to fix the tube. A small safety-pin is inserted through the wall of the tube at the level of the upper lip to ensure its placement. The pin is then covered with elastoplast to avoid metal contact with the nasal septum, and then another strip of tape fixes it to the upper lip (Figure 7).

2. The tube is then cut almost flush with the nose, and no connector is inserted. The child is thus unable to grasp the tube to pull it out.

3. The child's arms should be restrained at the elbow (Figure 8). This allows freedom to move the arms and to use the hands as desired, but prevents flexing of the elbows, so that the nose is out of reach and the tube cannot be pulled out. We find that a slab of "San Splints" $\$$ moulded over two-thirds of the length and diameter of the padded arm, and strapped with elastoplast, is very effective.

*Portex division, Smiths Industries Inc., Wil. mington, Ma 01887, U.S.A.

†Shiley Laboratories Inc., Irvine, California 92713 , U.S.A.

†Smith \& Nephew Ltd., Lachine, Quebec, Canada. 
TABLE I

Recommended Tube Sizes for Patients WITH ACUTE EPIGlotTITIS

\begin{tabular}{lc}
\hline \multicolumn{1}{c}{ Age } & $\begin{array}{c}\text { Tube size (I.D.) } \\
\text { mm. }\end{array}$ \\
\hline 0-6 months & 3.0 \\
6 months-2 years & 3.5 \\
2 years-4 years & 4.0 \\
Over 4 years & 4.5 \\
\hline
\end{tabular}

4. The presence of the nasotracheal tube is usually well tolerated after the first few hours. To prevent the initial agitation of the child, which might lead to accidental extubation and further irritation of the larynx, we administer diazepam $0.1 \mathrm{mg} / \mathrm{kg}$ intravenously in the operating room before the child begins to wake up. Rectal pentobarbitone (Nembutal) in a dose of 3 to $5 \mathrm{mg} / \mathrm{kg}$ is given as necessary in the intensive care unit during the first 12 hours of intubation.

Before putting on the arm restraints a blood culture specimen is taken and the intravenous administration of antibiotics is started in the operating room.

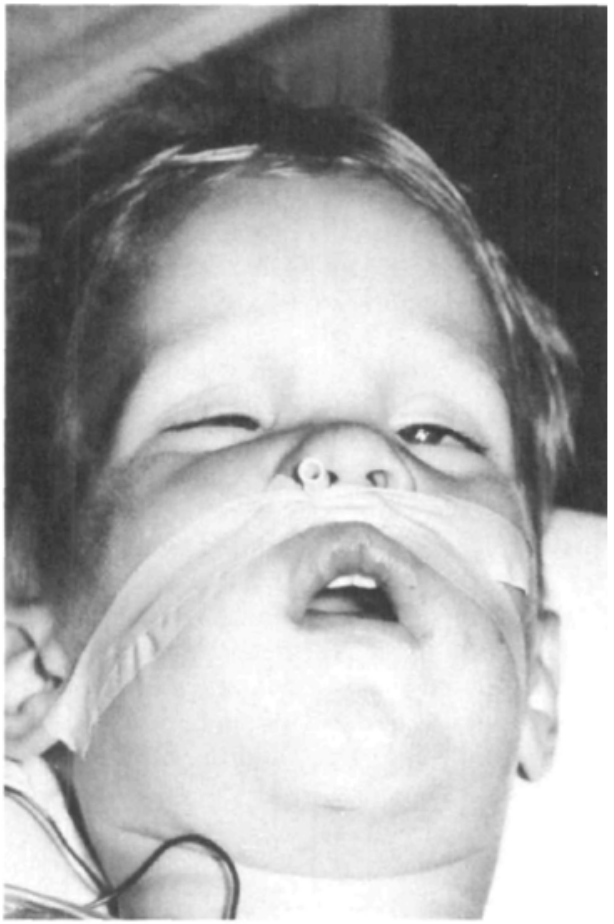

FIGURE 7 Fixation of the tube in acute epiglottitis.

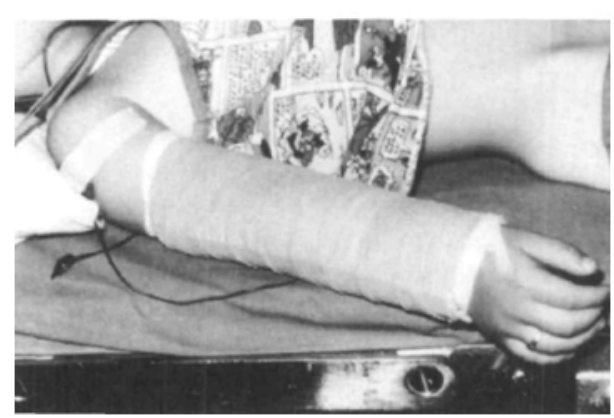

FIGURE 8 Restraining of the arms in acute epiglottitis.

Because $H$. influenzae is usually the responsible organism, ampicillin is prescribed in a dose of 200 $\mathrm{mg} / \mathrm{kg}$ daily, given in divided doses every six hours and continued orally for one week after the child is discharged from the hospital. In more severe cases, or if there is no initial response to ampicillin, chloramphenicol is added.

It is important to prevent tracheal secretions from accumulating and blocking the lumen of the tracheal tube. This is achieved by nursing the child in a croupette, by the instillation of saline into the tube every half-hour and by suctioning of secretions under sterile conditions every hour. Some workers in Australia have found that, with proper suctioning, a croupette was not needed. In our cases this was not enough and has led to crusting of secretions and obstruction of the lumen of the tube. It may be that excessive dryness of our heated air-conditioned buildings necessitates the extra humidification provided by a croupette.

The child is kept fasting during the period of intubation and for three hours after extubation. Intravenous maintenance fluids are given for hydration during this period. Aspirin suppositories are given to control high fever.

\section{Extubation}

The decision to extubate the trachea is usually made by the anaesthetist based on the following criteria:

1. Improvement of the Toxaemia. The child starts to feel well, sits up and shows interest in his surroundings. The fever subsides and pulse rate slows.

2. Examination of the Larynx. A direct laryngoscopy is done in the bed after 75 to $100 \mathrm{mg}$ of thiopentone, 24 hours following intubation. The size of the epiglottis and the degree of inflammation are noted and compared to the initial findings 
TABLE II

Nasotracheal Intubation In Acute Epiglottitis: COMPLICATIONS IN 47 CASES (1975-1977)

\begin{tabular}{lc}
\hline \hline Prior to nasotracheal intubation: & \\
$\quad$ Lobar Pneumonia & 1 \\
During intubation & \\
$\quad$ Accidental extubation & \\
$\quad$ reintubated 3 & \\
$\quad$ observed 2 & 2 \\
Blocked tube (secretions) & 4 \\
Neck swelling (adenitis or oedema) & 2 \\
Endobronchial intubation (on X-ray) & 4 \\
Atelectasis on X-ray & 1 \\
Radiological picture of aspiration & 1 \\
Extreme restlessness & 1 \\
Persistent vomiting & 1 \\
Early complications following extubation: & 1 \\
Pleural effusion (Viral) & \\
Persistent vomiting and diarrhea & None \\
Late complications on follow-up: & None \\
On clinical examination alone (30 cases) & \\
On clinical and endoscopic examination (13 cases) &
\end{tabular}

at the time of intubation. To facilitate comparison and follow-up by different members of the staff, the following grading is suggested:

Grade 1. Slightly swollen epiglottis, with no difficulty in visualizing the vocal cords.

Grade 2. Moderate swelling, involving the arytenoids and ary-epiglottic folds.

Grade 3. Very swollen epiglottis, but supraglottic structures easily identifiable.

Grade 4. Complete distortion of supraglottic appearance. One of the interesting features of epiglottitis is the lack of correlation between the size of the swollen epiglottis and the degree of respiratory difficulty. This again stresses the importance of the generalized toxaemia in producing respiratory distress. With medical treatment the acute course of epiglottitis subsides in approximately 24 hours. The child should then be ready for extubation within 24 to 48 hours.

We believe that the best indication for extubation is the disappearance of manifestations of toxaemia, even if the epiglottis is still slightly swollen. A leak around the tube should not be a criterion for extubation, because, unlike croup patients, the small size of the tube used should allow a continuous leak throughout. Also, the amount of secretion in the airway may not be reduced until the tube has actually been removed.

Using these criteria, and with more experience, there has been a tendency to early extubation in these cases. In no instance has it been necessary to re-intubate the trachea in any patient in this series. As prophylaxis against the possible development of post-intubation "croup", all patients were given an intramuscular injection of dexamethasone 4 to $8 \mathrm{mg}$ half an hour before extubation."

\section{RESULTS}

The first obvious difference between nasotracheal intubation and tracheostomy in establishing the airway in patients with acute epiglottitis is the duration of treatment. Tracheostomy patients had a mean cannulation time of seven days and a mean hospital stay of nine days. Those treated with nasotracheal intubation were intubated for a mean duration of 48 hours and had a mean hospital stay of five days.

There were no deaths with either method of treatment. The complications recorded while using nasotracheal intubation are listed in Table II. They were all minor and most related to accidental extubation or blocking of the lumen of the tube. Later in the series this was almost completely avoided by careful attention to the details of fixing the tube and to humidification. Thirty patients were seen in the otolaryngology clinic following discharge and had normal findings on clinical examination. Thirteen of these (mostly during the earlier part of the series) were readmitted for follow-up laryngoscopy and bronchoscopy under general anaesthesia, two while undergoing other incidental operations. The endoscopic findings were reported normal in all of them and it was not felt justifiable to continue the policy of endoscopic follow-up unless there was a specific indication. The morbidity in patients 
TABLE III

Complications of Tracheostomy In ACUte Epiglottitis. (61 CASES 1966-1974)

\begin{tabular}{ll}
\hline Preoperative: & \\
$\quad$ Aspiration pneumonia on X-ray & 7 \\
Operative: & 1 \\
Pneumothorax (requiring chest drain) & 0 \\
Haemorrhage & 18 \\
Early post-operative: & 12 \\
$\quad$ Pneumo-mediastinum on X-ray & 9 \\
Pneumonia & 7 \\
Surgical emphysema of the neck & 1 \\
Atelectasis on X-ray & 2 \\
Pleural effusion (requiring drainage) & 1 \\
Tracheal Obstruction & 2 \\
requiring revision of tracheostomy & 1 \\
Accidental decannulation & 4 \\
$\quad$ requiring revision of tracheostomy & 1 \\
Delayed decannulation & 1 \\
Mediastinitis & \\
Peri-tracheostomal infection & 7 \\
Late complications: & 3 \\
Related to wide scar, or keloid & 4 \\
requiring plastic surgical revision & \\
Persistent stomal granuloma up to one year & 4 \\
\hline
\end{tabular}

treated by tracheostomy in our hospital was reviewed by Pashley \& Baxter ${ }^{7}$ and is summarized in Table III. The incidence of major complications was 19.5 percent, with two patients accounting for almost one-third of all these complications. It is to be noted that although there were no deaths in this group, many of these complications are potentially life-threatening. Such complications were tension pneumothorax, tracheal obstruction, mediastinitis and early accidental decannulation requiring urgent revision of the tracheostomy.

Of 61 patients reviewed, 32 had a follow-up clinical examination. None had clinical evidence of tracheal stenosis and none of them underwent endoscopic examination of the airway. The late complications were related mostly to scar (7 cases) and three patients required plastic surgery for scar revision.

\section{Discussion}

In contrasting tracheostomy and nasotracheal intubation for the treatment of airway obstruction in acute epiglottitis, three different points of view must be considered:

1. The parents' point of view. Provided that the safety of the child is not jeopardized, all parents questioned would prefer their children not to have a surgical scar in the neck. Most of the late complications of tracheostomy were scar-related and in five per cent of cases plastic surgical revision of the scar was necessary.

2. The hospital administrator's point of view. With the current soaring cost of hospitalization, nasotracheal intubation in acute epiglottitis offers the advantage of much shorter hospitalization, with mean stay of five days compared to nine days for children having tracheostomy.

3. The medical point of view. Nasotracheal intubation is an easier procedure when performed by experienced anaesthetists and avoids the operative and post-operative complications of tracheostomy.

\section{Conclusion}

From this review we can conclude that both tracheostomy and nasotracheal intubation are safe methods of establishing the airway in patients with acute epiglottitis. There were no deaths in these series with either approach.

The incidence of complications and morbidity of tracheostomy is small, but appreciably more significant and more life-threatening than those after nasotracheal intubation. An artificial airway should be established in all patients with acute epiglottitis. Nasotracheal intubation is the treatment of choice. However, tracheostomy can still be indicated in some cases, and would be a safe 
alternative in places where the nursing staff is not familiar with handling nasotracheal tubes and keeping them patent.

\section{SUMMARY}

Forty-seven patients treated for acute epiglottitis by nasotracheal intubation under general anaesthesia following a preset protocol are presented. The results are compared with 61 cases treated by tracheostomy following induction of general anaesthesia and intubation in the same institution. Both groups were followed clinically, and 13 of the children treated by nasotracheal intubation alone had a follow-up endoscopic examination of the larynx. There was no mortality in either group, but the morbidity was significantly higher in the children who had tracheostomy.

Details of the management protocol are presented. Only inhalation anaesthetic agents are recommended and it is concluded that children with acute epiglottitis should always have an artificial airway inserted. Nasotracheal intubation seems to be associated with less morbidity than tracheostomy in experienced hands.

\section{RÉSUMÉ}

On rapporte ici une série de 47 enfants ayant présenté une épiglottite aigïe et chez qui l'on a procédé à une intubation par voie nasotrachéale, sous anesthésie générale, conformément à un protocole établi à l'avance. Les résultats obtenus chez ces patients ont été comparés à ceux obtenus chez 61 patients atteints également d'épiglot tite aigüe et trachéostomisés sous anesthésie générale.

L'évolution clinique des malades de ces deux séries a été comparée. De plus, 13 des enfants non trachéostomisés ont eu un examen laryngoscopique lors d'une visite de contrôle après leur hospitalisation.
Aucune mortalité n'est survenu chez les malades de l'une et l'autre série. La morbidité a cependant été plus élevée et ce de façon significative chez les enfants trachéostomisés.

Une voie aérienne artificielle (intubation ou trachéostomie) devrait être établie dans tous les cas d'épiglottite aigüe. Seulement des anesthésiques d'inhalation devraient être utilisés chez de tels patients. Dans un milieu expérimenté, l'intubation nasotrachéale semble donner lieu à une morbidité moins élevé que la trachéostomie.

\section{ACKNOWLEDGEMENTS}

We wish to thank Dr. Graham E. Dutton, whose enthusiasm and persistence made this study possible, and the members of the Departments of Anaesthesia, Otolaryngology and Medicine at The Montreal Children's Hospital for their support.

\section{REFERENCES}

I. Sinclair, S.E. H. influenza (Type B) in acute laryngitis with Bacteremia. J.A.M.A. 1/7: 170 (1941).

2. BAXTER, J.D. Acute epiglottitis in children. Laryngoscope 77: 1358 (1967)

3. Hawkins, D., Miller, A., Sachs, G. \& Benz, R. Acute epiglottitis in adults. Laryngoscope 83: 1211 (1973).

4. Dunbar, J.S. Epiglottitis and croup. J. Can. Assoc. Radiol. 12: 86(1961).

5. JONES, H.M. Acute epiglottitis. Practitioner 178 (1957).

6. ADAIR, JoHN C. \& RiNG, W.H. Management of epiglottitis in children. Anesthesia and Analgesia 54:622 (1975).

7. Pashley, N.R.T. \& Baxter, J.D. Acute epiglottitis in children, the morbidity of management by elective tracheostomy. Personal Communication.

8. Allen, T.H. \& Stevens, I.M. Prolonged endo tracheal intubation in infants \& children. British J. Anaesthesia 37: 566 (1965).

9. Jordan, W.S., Graves, C.L., \& Elwyn, R.A. New therapy for post-intubation laryngeal edema \& tracheitis in children. J.A.M.A. 2/2:585(1970). 